\title{
Vertical water body effect of benzene hexachloride
}

\author{
Dongfang Yang1,2,3, Fengyou Wang1,2, Huozhong He1,2, Sixi \\ Zhu1,2 and Yunjie Wu1,2 \\ 1Research Center for Karst Wetland Ecology, Guizhou Minzu University, \\ Guizhou Guiyang, Guizhou Guiyang, China \\ 2College of Chemistry and Environmental Science, Guizhou Minzu \\ University, Shanghai, 550025, China \\ 3 North China Sea Environmental Monitoring Center, SOA, Qingdao \\ 266033, China \\ dfyang_dfyang@126.com
}

\begin{abstract}
Based on the analysis on the transfer process of benzene hexachloride $(\mathrm{HCH})$, this paper proposed the theory of vertical water body effect, vertical water body cumulative effect, and vertical water body dilutive effect, including definition, main function, and concept model. Furthermore, this paper applied vertical water body effect in analyzing the transfer processes of HCH in Jiaozhou Bay Waters. Results showed that this theory was useful and effective in revealing the changes of $\mathrm{HCH}$ under the effects of vertical water body.
\end{abstract}

Keywords: Benzene hexachloride; Vertical water body; Cumulative effect; Dilutive effect; Jiaozhou Bay

\section{Introduction}

$\mathrm{HCH}$ used to be one of the widely used pesticides, and had been recognized as one of the persistent organic pollutants (POPs). Ocean is the sink of various pollutants. Researching the transfer process of $\mathrm{HCH}$ is essential to understand the persistent pollution caused by $\mathrm{HCH}$ [1-13].

Jiaozhou Bay is a semi-closed bay, located in the south of Shandong Province, eastern China $\left(35^{\circ} 55^{\prime}-36^{\circ} 18^{\prime} \mathrm{N}, 120^{\circ} 04^{\prime}-120^{\circ} 23^{\prime} \mathrm{E}\right)$. There are both economic developed regions (Qingdao etc.) and agricultural developed regions (Jiaonan etc.) [3]. Previous studies showed that this bay has been polluted by $\mathrm{HCH}$, and the transfer processes of $\mathrm{HCH}$ were research hotspots [1-13].

In order to provide theory and methodology to better understand the transfer processes of $\mathrm{HCH}$, this paper proposed the theory of vertical water body effect, vertical water body cumulative effect, and vertical water body dilutive effect, including definitions, main functions, and concept model. Furthermore, based on investigation data on $\mathrm{HCH}$ in Jiaozhou Bay water in April, July and October 
1982 [14], this paper applied vertical water body effect in analyzing the transfer processes of $\mathrm{HCH}$ in Jiaozhou Bay Waters.

\section{Background of vertical water body effect}

$\mathrm{HCH}$ is difficult to dissolve in water, yet is absorbable to suspended particulate matter, plankton and sediment [15] The growth and reproduction of marine organism (especially phytoplankton) are increasing from spring and reaching the peak in summer [16]. The growth and reproduction of phytoplankton generate a lot of colloid, enhance the adsorption capacity of the suspended particulate matter, and increase the sedimentation of $\mathrm{HCH}$. Hence, $\mathrm{HCH}$ contents in surface waters is closed to bottom waters, and the vertical distribution is homogenous. What is more, $\mathrm{HCH}$ contents in both surface and bottom waters in summer are higher than in spring. By means of sedimentation, high $\mathrm{HCH}$ content in surface waters leads to high $\mathrm{HCH}$ content in bottom waters. Generally speaking, during the transferring from surface water to bottom waters, $\mathrm{HCH}$ content is changing. In order to quantitatively reveal the changing process, the vertical water body effect was proposed.

\section{Definition of vertical water body effect}

During the transfer process from surface waters to bottom waters, the effects of water body are militating, leading to the changing of $\mathrm{HCH}$ content. We defined this phenomenon as vertical water body effect. In case of during the transfer process from surface waters to bottom waters, by means of the effects of water body, $\mathrm{HCH}$ contents were decreasing. We defined this phenomenon as vertical water body dilutive effect. If $\mathrm{HCH}$ contents were increasing. We defined this phenomenon as vertical water body cumulative effect. Here, we described these effects as in Fig. 1. 


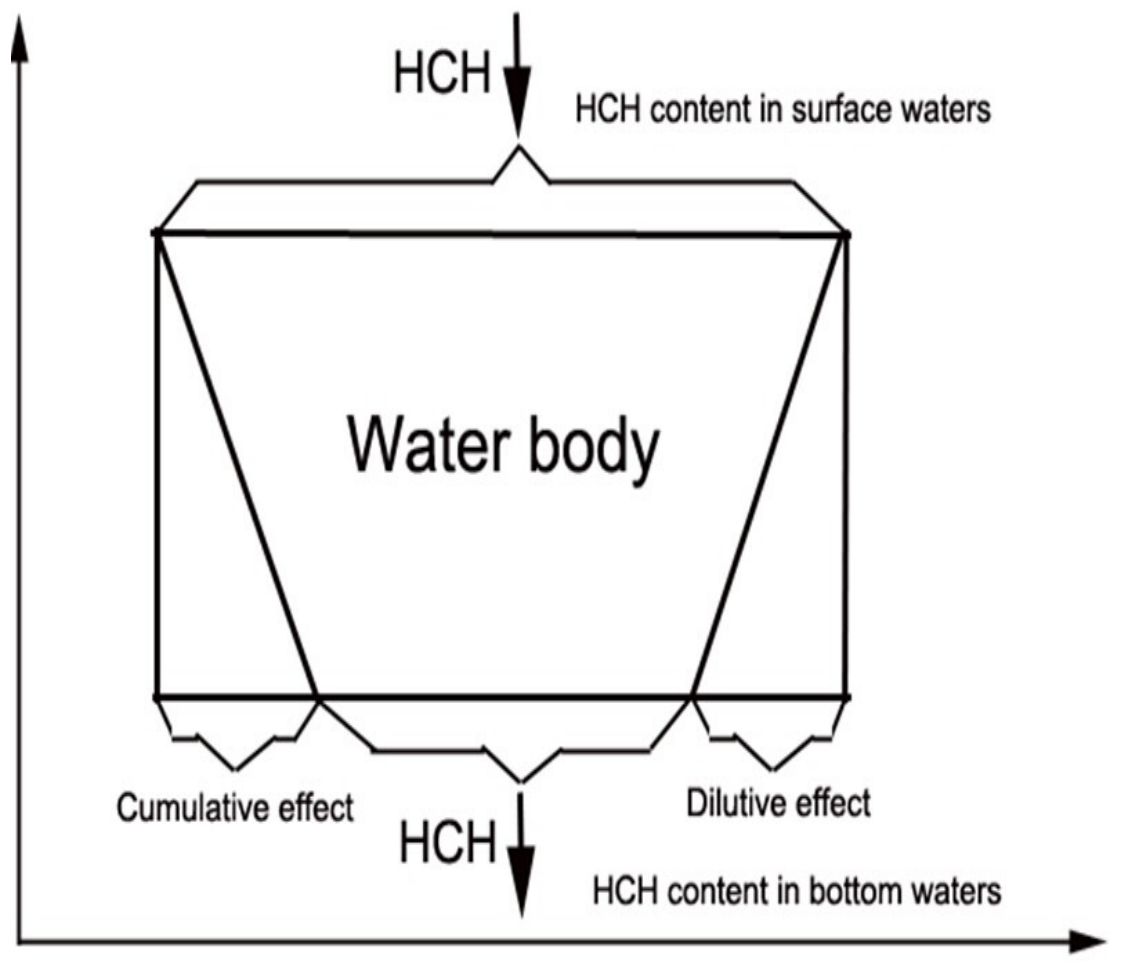

Fig. 1 Concept model of vertical water body effect

\section{Main function of vertical water body effect}

It is necessary to understand the effects of water body on $\mathrm{HCH}$ contents during the transferring of $\mathrm{HCH}$ from surface waters to bottom waters. Hence, based on the $\mathrm{HCH}$ contents in surface waters and bottom waters, in addition of theory of vertical water body effect, vertical water body cumulative effect, and vertical water body dilutive effect, the changing of $\mathrm{HCH}$ contents could be easily to be determined.

\section{Theory of vertical water body effect}

In case of $\mathrm{HCH}$ contents in surface waters (a) are lower than in bottom waters (b). Where, a is the lowest value of $\mathrm{HCH}$ contents in surface waters, b is the highest value of $\mathrm{HCH}$ contents in bottom waters, $\mathrm{a}<\mathrm{b}$. The reason is that a large amount of $\mathrm{HCH}$ is subsided to the bottom waters, leading to the accumulation of $\mathrm{HCH}$ in bottom waters. The vertical water body cumulative effect is that, after passing the water body, $\mathrm{HCH}$ contents in waters are changed from the lowest value in surface waters (a) to the highest value in bottom waters (b). 
In case of $\mathrm{HCH}$ contents in surface waters (a) are higher than in bottom waters (b). Where, a is the highest value of $\mathrm{HCH}$ contents in surface waters, b is the lowest value $\mathrm{HCH}$ contents of $\mathrm{HCH}$ in bottom waters, $\mathrm{a}>\mathrm{b}$. The reason is that in addition of the migrating down of $\mathrm{HCH}$, a large amount of $\mathrm{HCH}$ is subsided to the sediments, and is finally removed from water body. Hence, $\mathrm{HCH}$ contents in bottom waters (b) were lower than in surface waters (a). The vertical water body dilutive effect is that, after passing the water body, $\mathrm{HCH}$ contents in waters are changed from the highest value in surface waters (a) to the lowest value in bottom waters (b).

\section{Application of vertical water body effect}

$\mathrm{HCH}$ contents in Jiaozhou Bay surface waters and bottom waters in April 1982 ranged from $0.065-0.301 \mu \mathrm{g} . \mathrm{L}-1$ and $0.072-0.302 \mu \mathrm{g} . \mathrm{L}-1$, respectively (Table 1). The vertical water body effect was cumulative for lowest values, that was $0.072-0.065=0.007 \mu \mathrm{g} . \mathrm{L}-1$. For highest values, the vertical water body effect was cumulative, that was $0.302-0.301=0.001 \mu$ g.L- 1 . Hence, it could be concluded that the vertical water body effect was in April was cumulative, that was 0.001-0.007 $\mu \mathrm{g} . \mathrm{L}-1$.

$\mathrm{HCH}$ contents in Jiaozhou Bay surface waters and bottom waters in July 1982 ranged from $0.171-0.409 \mu \mathrm{g} . \mathrm{L}-1$ and $0.160-0.254 \mu \mathrm{g} . \mathrm{L}-1$, respectively (Table 1). Both lowest and highest of $\mathrm{HCH}$ contents in surface waters were higher than in bottom waters, indicated that the vertical water body effect was in July was dilutive, that was 0.011-0.155 $\mu \mathrm{g}$.L-1.

$\mathrm{HCH}$ contents in Jiaozhou Bay surface waters and bottom waters in October 1982 ranged from $0.136-0.211 \mu \mathrm{g} . \mathrm{L}-1$ and $0.129-0.206 \mu \mathrm{g} . \mathrm{L}-1$, respectively (Table 1). In the same way as in July, the vertical water body effect was in October was dilutive, that was 0.005-0.007 $\mu$ g.L-1.

For the whole year of 1982, HCH contents in Jiaozhou Bay surface waters and bottom waters ranged from $0.065-0.409 \mu \mathrm{g} . \mathrm{L}-1$ and $0.072-0.302 \mu \mathrm{g} . \mathrm{L}-1$, respectively (Table 1 ). The vertical water body cumulative effect was $0.072-0.065=0.007 \mu \mathrm{g} . \mathrm{L}-1$, and the vertical water body dilutive effect was $0.409-0.302=0.107 \mu \mathrm{g} . \mathrm{L}-1$. It could be concluded that for the whole year of 1982 , the vertical water body effect was cumulative for lowest values, and dilutive for highest values.

Table 1 The vertical water body effect of HCH in Jiaozhou bay 1982

\begin{tabular}{ccccc}
\hline $\begin{array}{c}\mathrm{HCH} \\
\text { content } / \mu \mathrm{g} \cdot \mathrm{L}-1\end{array}$ & April & July & October & Yearly \\
\hline Surface waters & $0.065-0.301$ & $0.171-0.409$ & $0.136-0.211$ & $0.065-0.409$ \\
Bottom waters & $0.072-0.302$ & $0.160-0.254$ & $0.129-0.206$ & $0.072-0.302$ \\
Effect & Cumulative & Dilutive & Dilutive & $\begin{array}{c}\text { Cumulative and } \\
\text { dilutive }\end{array}$ \\
\hline
\end{tabular}




\section{Conclusion}

We took $\mathrm{HCH}$ as the indicator of water body, analyzed the effects of water body on $\mathrm{HCH}$ contents during the transferring of $\mathrm{HCH}$ in water body. We proposed the theory of vertical water body effect, vertical water body cumulative effect, and vertical water body dilutive effect, including definition, main function, and concept model. Results of the case study showed that this theory was useful and effective in revealing the changes of $\mathrm{HCH}$ under the effects of vertical water body.

\section{Acknowledgement}

This research was sponsored by Education Ministry's New Century Excellent Talents Supporting Plan (NCET-12-0659), Project of Outstanding Technological Educators of Governor of Guizhou ([2012]71), Project of Low Carbon Technology Plan of Guiyang (2012205]), Project of Science and Technology Foundation of Guiyang (LKM[2012]05), Special Research Projects of High Level Talents of Guizhou Province (TZJF-2011-44), Scientific Research Foundation of Guizhou Minzu University (Research on the drive mechanism of the changing of Guizhou wetlands).

\section{References}

[1] D.F. Yang, Z.H. Gao, H.R. Cao, G.Y. Wen and L.L. Sun: Coast. Engin., Vol.27(2008), p.65-71. (in Chinese)

[2] D.F. Yang, Z.H. Gao, P.Y. Sun, L.L. Wang and L. Xie: Coast. Engin., Vol.28(2009), p.69-77. (in Chinese)

[3] D.F. Yang, Z.H. Gao, H. Huang, J.H. Guo and Y.C. Zhang: Coast. Engin., Vol.28(2009), p.69-77. (in Chinese)

[4] D.F. Yang, Q. Shi, J.H. Guo, W. Tang and Z.R. Ding: Coast. Engin., Vol.29(2010), p.59-66. (in Chinese)

[5] D.F. Yang, J.H. Guo, Z.R. Ding, S.Y. Wu and Q. Shi: Coast. Engin., Vol.29(2010), p.62-69. (in Chinese)

[6] D.F. Yang, Y. Chen, S.Y. Wu, Z.R. Ding and Q. Shi: Mar. Sci., Vol.34(2010), p.59-66. (in Chinese)

[7] D.F. Yang, Z.Q. Miao, Z.R. Ding, H.Z. Xu and G.T. Cao: Mar. Sci., Vol.35(2011), p.112-116. (in Chinese)

[8] D.F. Yang, Z.R. Ding, L. Zheng, Z.G. Bu and Q. Shi: Coast. Engin., Vol.32(2011), p.66-74. (in Chinese)

[9] D.F. Yang, L. Zheng, H.H. Jiang, Q. Shi and Z.R. Ding: Coast. Engin., Vol.30(2011), p.56-65. (in Chinese) 
[10] D.F. Yang, Z.R. Ding, Q. Shi, Y. Chen and Y.C. Zhang: Frontiers of Earth Science, Vol. 2(2012), p.31-36. (in Chinese)

[11] D.F. Yang, Z.Q. Miao, H.Z. Xu, Z.R. Ding and H.Y. Hu: Ocean Devel. Manag., Vol. 30(2013),p:46-50. (in Chinese)

[12] D.F. Yang, Z.Q. Miao, A.Y. Song, J.Y. Sun and P. Gao: Coast. Engin., Vol.31(2012), p.62-75. (in Chinese)

[13] Y. Chen, Z.R. Ding, L. Zheng, Y.J. Zhang and D.F. Yang: Procedia Environmental Sciences, Vol. 16(2012), p. 271-278.

[14] China's State Oceanic Administration: The specification for marine monitoring (Ocean Press, Beijiang 1991), p.1-300. (in Chinese)

[15] H.K. Gu: Marine chemical of Bohai Sea and Yellow Sea (Science Precess 1990) . (in Chinese)

[16] D.F. Yang, F. Wang, Z.H. Gao, W.L. Cui and S.X. Huo: Mar. Sci., Vol. 28(2004),p.71-74. (in Chinese) 